\title{
Penghargaan dan sanksi terhadap kinerja karyawan PT. Agung Toyota Cabang Pangkalan Kerinci
}

\author{
Agus Supriyadi \\ Prodi Manajemen, Sekolah Tinggi Ilmu Ekonomi Indragiri Rengat \\ E-mail korespodensi: agussupriyadi@stieindragiri.ac.id
}

\begin{abstract}
Human resources play a critical part in accomplishing a company's aims and goals. Efforts to recruit professional individuals are inextricably linked to how leaders manage their human resources to meet organizational objectives as a company engaged in selling various series cars, PT. Agung Toyota Pangkalan Kerinci Branch has been committed to delivering incentives and punishments to its personnel in its activities. In actuality, the company's product sales target has been decreasing year after year. As a result, this research aimed to see if coupling Reward and Punishment had a substantial impact on staff performance at the PT. Agung Toyota Pangkalan Kerinci Branch. The study followed a quantitative approach, utilizing multiple linear regression analysis to determine the effect. Questionnaires and interviews were undertaken to acquire primary data, and some extra data was used as preliminary data. According to the findings, rewards have a considerable impact on employee performance, and punishment has a significant effect on employee performance.
\end{abstract}

Keywords: Reward, Punishment, Employee performance

\begin{abstract}
Abstrak
Sumber daya manusia memiliki peranan penting dalam mencapai tujuan dan sasaran perusahaan. Usaha untuk mendapatkan tenaga yang profesional tentunya tidak terlepas dari bagaimana pemimpin mengatur sumber daya manusia yang dimilikinya agar tercapainya tujuan organisasi. PT. Agung Toyota Cabang Pangkalan Kerinci sebagai perusahaan yang bergerak dibidang penjualan mobil bermacam seri yang sudah berkomitmen dalam memberikan penghargaan (reward) dan sanksi (punishment) kepada karyawannya dalam aktivitas perusahaannya. Namun dalam praktiknya, target penjualan produknya mengalami penurunan setiap tahunnya. Oleh karena itu tujuan penelitian ini adalah untuk melihat pengaruh Reward (Penghargaan) dan Punishment (Sanksi) secara simultan berpengaruh signifikan terhadap kinerja karyawan pada PT. Agung Toyota Cabang Pangkalan Kerinci. Penelitian dilakukan dengan pendekatan kuantitatif dengan menggunakan analisis regresi linear berganda. Kuesioner dan wawancara dilakukan untuk mendapatkan data primer dan beberapa data tambahan digunakan sebagai data primer. Hasil temuan penelitian menyebutkan bahwa bahwa Penghargaan berpengaruh signifikan terhadap kinerja karyawan dan sanksi juga berpengaruh signifikan terhadap kinerja karyawan.
\end{abstract}

Kata kunci : Penghargaan, Sanksi, Kinerja karyawan

\section{PENDAHULUAN}

Sumber daya manusia memiliki peranan sentral dalam mengembangkan dan mencapai sasaran organisasi. Harmoni dalam tata hubungan antar manusia baik antar sesama karyawan maupun hubungan atasan bawahan juga menjadi penting untuk dimiliki 
perusahaan. Usaha untuk mendapatkan tenaga yang profesional sesuai dengan tuntutan jabatan diperlukan suatu pembinaan yang berkesinambungan, yaitu usaha kegiatan perencanaan, pengorganisasian, penggunaan, dan pemeliharaan tenaga kerja agar mampu melaksanakan tugas dengan efektif dan efisien.

PT. Agung Toyota Cabang Pangkalan Kerinci sebagai perusahaan swasta juga menjalankan tugas dan fungsinya secara maksimal. Pengembangan sumber daya manusia didalamnya juga dilakukan, salah satunya adalah pembinaan karyawannya. Sebagai langkah nyata dalam hasil pembinaan, maka diadakan pemberian penghargaan (reward) karyawan yang telah menunjukkan prestasi kerja yang baik. Adapun penghargaan yang diberikan diuraikan pada Tabel 1 sebagai berikut:

Tabel 1. Daftar penghargaan untuk setiap penjualan produk

\begin{tabular}{ccc}
\hline No & Tipe kendaraan & Bonus (Rp) \\
\hline 1. & Agya & 2.000 .000 \\
2. & Calya & 2.500 .000 \\
3. & Avanza & 3.000 .000 \\
4. & Rush & 4.000 .000 \\
5. & Innova & 5.000 .000 \\
6. & Fortuner & 6.000 .000 \\
\hline
\end{tabular}

Sumber: PT. Agung Toyota Cabang Pangkalan Kerinci Kabupaten Pelalawan, 2021.

Dari Tabel 1 dapat dilihat daftar penghargaan (reward) berupa bonus untuk setiap penjualan mobil berbagai tipe. Semakin tinggi harga sebuah produk mobil Toyota, maka akan semakin besar bonus yang didapatkan untuk setiap penjualannya. Pemberian penghargaan (reward) tersebut merupakan upaya perusahaan dalam memberikan balas jasa atas hasil kerja karyawan, sehingga dapat mendorong karyawan bekerja lebih giat dan berpotensi (Hidayat, 2018). Hal ini wajar dilakukan, karena karyawan memerlukan suatu penghargaan pada saat hasil kerjanya telah memenuhi bahkan melebihi standar yang telah ditentukan oleh perusahaan.

Penghargaan merupakan sebuah imbalan yang diberikan dalam bentuk material dan non material yang diberikan oleh pihak perusahaan kepada karyawannya agar mereka dapat bekerja dengan sanksi yang tinggi dan berprestasi dalam mencapai tujuan-tujuan perusahaan (Adolfina \& Uhing, 2017). Dengan kata lain, pemberian penghargaan ditujukan untuk meningkatkan produktivitas dan mempertahankan karyawan yang berprestasi agar tetap berada dalam perusahaan. Pemberian sistem penghargaan dimaksudkan sebagai dorongan agar karyawan mau bekerja dengan lebih baik dan membangkitkan sanksi sehingga dapat mendorong kinerja Karyawan menjadi lebih baik (Astuti et al., 2018). Hal ini juga dibenarkan oleh Pramesti et al (2019) yang mengatakan bahwa dengan adanya penghargaan dan sanksi membuat karyawan lebih gembira dan produktif lagi dalam melakukan pekerjaannya dan tidak melaksanakan hal-hal yang di inginkan dalam bekerja.

Dalam mengukur penghargaan berupa (1). Gaji karyawan, (2). Penghargaan untuk karyawan, (3). Pujian, (4). Cuti karyawan, (5). Tunjangan karyawan (Kadarisman, 2012). Sedangkan Kumentas (2013) dalam Simamora (2006) membagi penghargaan menjadi 2 yaitu penghargaan instrinsik dimana didalamnya ada (instrinsic reward), berupa (1). perasaan kompetensi individu, (2). perasaan pencapaian dalam individu, (3). tanggung jawab dan otonomi individu, (4). Status, (5). Kepuasan kerja, (6). perasaan pengakuan informal. Sedangkan selanjutnya penghargaan ekstrinsik dimana ada (1). pembayaran 
insentif, (2). lingkungan kerja, (3). sanjungan dan pengakuan, (4). tunjangan karyawan, (5). pengakuan formal, (6). promosi jabatan, (7). gaji, (8). hubungan social.

Dari uraian diatas terlihat bahwa pemberian penghargaan yang jelas dan terarah yang tentu menjadi keinginan karyawan. Disamping itu juga, pemberian penghargaan tentunya berpengaruh positif terhadap kinerja karyawan. Hal ini dipertegas Ferdinand \& Satibi (2021) yang dalam penelitiannya berkaitan dengan pemberian penghargaan, dimana adanya pengaruh yang signifikan pada kinerja karyawan. Bukan itu saja, pengaruh penghargaan juga telah diuji reward berpengaruh positif dan signifikan terhadap kinerja karyawan (Yani, 2021).

Disamping itu, sanksi juga telah ditetapkan oleh PT. Agung Toyota Cabang Pangkalan Kerinci. Sanksi (punishment) merupakan bentuk penguatan yang sifatnya negative yang dimaksudkan untuk memberikan motivasi apabila diberikan secata benar dan tidak melanggar prinsip (Astuti et al., 2018). Sanksi yang diberikan pada karyawan terkadang tidak memberikan rasa jera, justru menimbulkan rasa dendam yang memancing emosi karyawan. Hal ini diwajarkan jika karyawan tidak memahami bahwa sanksi yang diberikan sebagai motivasi untuk meningkatkan kinerjanya (Adolfina \& Uhing, 2017). Hal ini juga disampaikan oleh Pramesti et al (2019) adanya sanksi sebagai pembatas perilaku karyawan untuk tidak melakukan perilaku yang tidak diinginkan. Sehingga terlihat jelas bahwa sebenarnya sanksi berpengaruh positif dan signifikan terhadap kinerja karyawan (Wirawan \& Afani, 2018).

Adapun kategori sanksi ringan diberikan kepada karyawan yang tidak bisa mencapai target bulanan berupa surat peringatan awal. Kemudian jika keadaan tidak berubah maka sanksi sedang seperti pemotongan insentif akan diberikan jika pencapaian target terjadi terus menerus hingga bulan keenam tanpa mengalami kenaikan. Dan selanjutnya jika dalam satu tahun target penjualan tidak bisa tercapai maka akan berakhir dengan pengeluaran sistem sebagai sanksi berat yang ada pada PT. Agung Toyota Cabang Pangkalan Kerinci Kabupaten Pelalawan. Untuk lebih jelas dapat dlihat pada Tabel 2 dibawah ini:

Tabel 2. Mekanisme pemberian sanksi

\begin{tabular}{ccc}
\hline No & Kategori sanksi & Jenis sanksi \\
\hline 1. & Ringan & Pemberian surat peringatan \\
2. & Sedang & Pemotongan insentif \\
3. & Berat & Pemutusan sistem \\
\hline
\end{tabular}

Sumber: PT. Agung Toyota Cabang Pangkalan Kerinci Kabupaten Pelalawan, 2020.

Dari data Tabel 2 diatas terlihat bahwa ada 3 kategori sanksi dan 3 jenis sanksi yang diberikan. Untuk kategori sanksi ringan jenis sanksi yang diberikan berupa pemberian surat peringatan. Sedangkan untuk kategori sedang dilakukan pemotongan insentif karyawan serta untuk kategori sanksi yang berat, justru diberikan sanksi pemutusan system.

Secara teoritis, seorang karyawan akan mendapatkan kepuasan kerja jika mempersepsikan bahwa imbalan yang diterimanya baik berupa gaji, insentif, tunjangan dan penghargaan lainnya yang tidak berbentuk materi atas pelaksanaan pekerjaan yang dilakukannya nilainya lebih tinggi dari pada pengorbanannya berupa tenaga dan ongkos yang telah dikeluarkannya untuk melaksanakan pekerjaan itu. Disamping itu, berikut 
dijelaskan gaji yang diberikan tahun 2019 yang uraiannya dijelaskan pada tabel 3 dibawah ini:

Tabel 3. Daftar gaji karyawan Tahun 2021

\begin{tabular}{ccc}
\hline No & Jabatan & Jumlah (Rp) \\
\hline 1. & Magang & 1.000 .000 \\
2. & Training & 2.700 .000 \\
3. & S1 & 3.200 .000 \\
4. & $\mathrm{C} 1$ & 3.500 .000 \\
5. & $\mathrm{~S} 2$ & 4.000 .000 \\
6. & SPV & 8.000 .000 \\
7. & KACAB & 15.000 .000 \\
\hline
\end{tabular}

Sumber:PT.Agung Toyota Cabang Pangkalan Kerinci Kabupaten Pelalawan, 2021(diolah)

Dari Tabel 3 diketahui jumlah gaji karyawan pada PT. Agung Toyota Cabang Pangkalan Kerinci Kabupaten Pelalawan. Gaji disesuaikan dengan masa kerja masingmasing karyawan. Level pertama dimulai dari karyawan magang sampai dengan jabatan tertinggi yaitu KACAB. Disini tingkat pendidikan tidak berpengaruh terhadap kenaikan jabatan pada PT. Agung Toyota Cabang Pangkalan Kerinci Kabupaten Pelalawan.

Untuk melihat target dan realisasi penjualan pada PT. Agung Toyota Cabang Pangkalan Kerinci Kabupaten Pelalawan dapat dilihat melalui Tabel 4 sebagai berikut:

Tabel 4. Target dan realisasi penjualan Tahun 2016-2020

\begin{tabular}{cccc}
\hline No & Tahun & $\begin{array}{c}\text { Target Penjualan } \\
\text { (unit) }\end{array}$ & Realisasi (unit) \\
\hline 1. & 2016 & 852 & 840 \\
2. & 2017 & 855 & 830 \\
3. & 2018 & 852 & 812 \\
4. & 2019 & 852 & 822 \\
5. & 2020 & 840 & 810 \\
\hline
\end{tabular}

Sumber: PT. Agung Toyota Cabang Pangkalan Kerinci Tahun 2021(diolah)

Berdasarkan Tabel 4 dapat dilihat bahwa dimilikinya target dalam penjualan yang harus dicapai setiap tahunnya. Pada tahun 2016 target penjualan mobil 852 unit dengan realisasi penjualan sebesar 840 unit. Pada tahun 2017 target penjualan sebesar 855 unit dan realisasi 830 unit. Pada tahun 2018 target penjualan sebanyak 852 unit dan realisasi penjualan sebanyak 812 unit jauh menurun dari realisasi penjualan tahun sebelumnya. Pada tahun 2019 target penjualan mobil sebanyak 852 unit dan realisasi penjualan sebanyak 822 unit. Pada tahun 2020 target penjualan mobil sebanyak 840 menurun dari target penjualan tahun sebelumnya serta realisasi penjualan mobil sebanyak 810 unit.

Kinerja dapat dikatakan sebagai hasil dari sebuah pekerjaan. Pekerjaan yang dilakukan terkait dengan target dan realisasi kerja yang dilakukan (D Afrizal, 2018). Pendapat lain, Pencapaian kinerja wujudnya dari tercapainya target dan tersebut tentunya dapat dilihat dari pencapaian target kerja yang telah ditetapkan (Wirawan \& Afani, 2018). Mangkunegara \& Prabu (2012) masalah kinerja dapat dilihat (1). Kualitas kerja, (2). Kuantitas kerja, (3). Tanggung jawab, (4). Kerja sama, (5). Inisiatif. Berdasarkan uraian maka penulis menetapkan tujuan penelitian yaitu bagaimana pengaruh penghargaan terhadap kinerja karyawan PT. Agung Toyota Cabang Pangkalan Kerinci. 


\section{METODE}

Penelitian dilakukan dengan pendekatan kuantitatif. populasi seluruh karyawan pada PT. Agung Toyota Cabang Pangkalan Kerinci Kabupaten Pelalawan Tahun 2020 yang berjumlah 85 orang. Penulis mengambil seluruh populasi dijadikan sampel dengan metode sensus atau sampel jenuh (Dedy Afrizal et al., 2021). Teknik pengumpulan data dengan angket yang disebarkan ke responden dan wawancara dengan respomden yang memahami dengan variable yang akan diteliti. Data yang dikumpulkan kemudian di analisis dengan analisis regresi linear sederhana dilakukan untuk melihat hubungan variable yang digunakan.

\section{HASIL DAN PEMBAHASAN}

Untuk mendapatkan hasil penelitian, data jawaban responden dianalisis dengan beberapa tahapan. Adapun tahapan yang dilakukan adalah sebagai berikut:

\section{Uji asumsi klasik}

Adapun tahap pertama yang dilakukan adalah dengan melakukan Uji asumsi klasik dengan tahapan uji normalitas, uji multikolinieritas dan uji heteroskedastisitas yang diuraikan sebagai berikut:

\section{Uji normalitas}

Untuk uji normalitas dapat dijelaskan pada Gambar 1 dibawah ini:

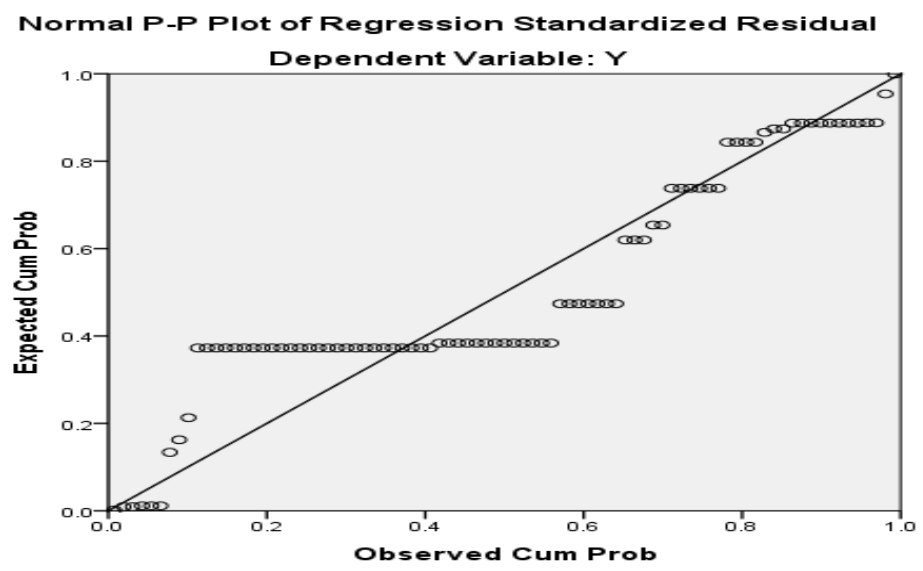

Gambar 1. Diagram normalitas data

Terlihat dari Gambar 1 diatas bahwa distribusi data mengikuti garis diagonal, yang artinyaadalah data mengikuti kriteria data normal.

Uji multikolinieritas

Dalam menguji Multikolinieritas dapat dijelaskan pada Tabel 5 dibawah ini:

Tabel 5. Uji multikolinieritas

Coefficients $^{\mathbf{a}}$

\begin{tabular}{|c|c|c|c|c|c|c|c|c|}
\hline & \multirow[t]{2}{*}{ Model } & \multicolumn{2}{|c|}{$\begin{array}{l}\text { Unstandardized } \\
\text { Coefficients }\end{array}$} & \multirow{2}{*}{$\begin{array}{c}\begin{array}{c}\text { Standardized } \\
\text { Coefficients }\end{array} \\
\text { Beta } \\
\end{array}$} & & \multirow[t]{2}{*}{ Sig. } & \multicolumn{2}{|c|}{$\begin{array}{l}\text { Collinearity } \\
\text { Statistics }\end{array}$} \\
\hline & & B & Std. Error & & & & Tolerance & VIF \\
\hline \multirow[t]{3}{*}{1} & (Constant) & .034 & .165 & & .208 & .836 & & \\
\hline & X1 & .774 & .063 & .624 & 12.304 & .000 & .623 & 6.050 \\
\hline & $\mathrm{X} 2$ & .633 & .085 & .377 & 7.424 & .000 & .623 & 6.050 \\
\hline
\end{tabular}

a. Dependent Variable: $\mathrm{Y}$

Sumber : Data diolah, 2021 
Dari data Tabel 5 terlihat bahwa nilai VIF sebesar $6,50<10$ dengan nilai tolerance sebesar $0,623>0,10$. Terlihat model regresi dalam penelitian ini tidak terjadi gejala korelasi antar variabel.

\section{Uji heteroskedastisitas}

Untuk uji heteroskedastisitas dapat dijelaskan pada Gambar 2 dibawah ini:

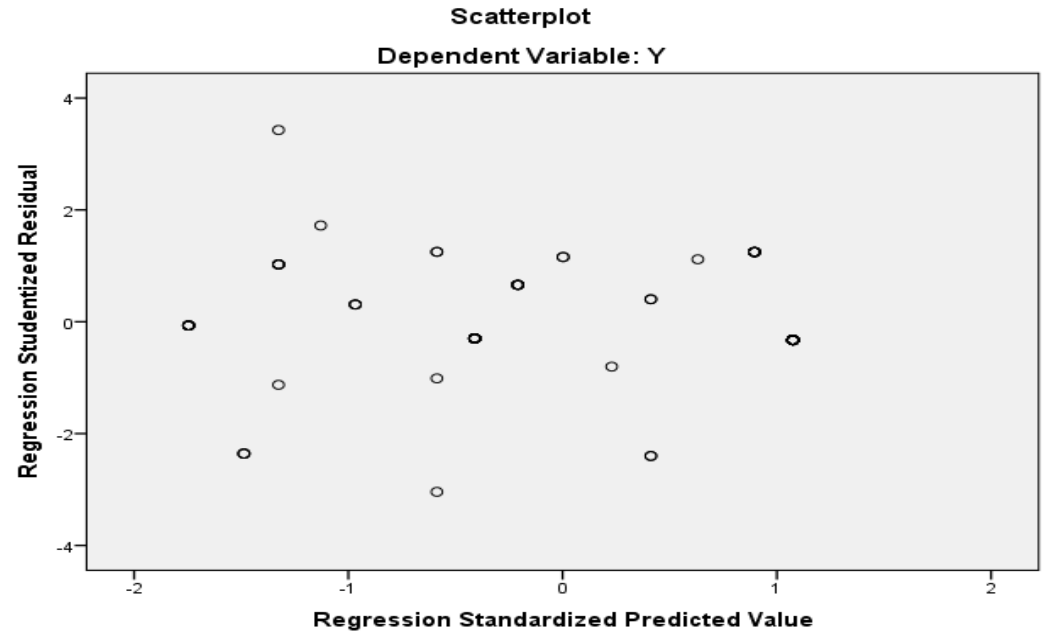

Gambar 2. Diagram scatterplot

Dari Gambar 2 dapat dilihat bahwa titik-titik menyebar secara acak tidak membentuk pola tertentu yang jelas, serta tersebar diatas dan dibawah angka nol (0) pada sumbu Y, maka model regresi bebas heteroskedasitas.

\section{Analisis regresi linear berganda}

Analisis regresi linear berganda merupakan salah satu analisis regresi yang variabel bebasnya lebih dari 1 variabel (Sugiyono., 2013). Analisis ini sangat sesuai digunakan untuk melihat pengaruh variable independent terhadap variable dependen suatu penelitian. Untuk lebih jelasnya akan diuraikan sebagai berikut:

\section{Koefisien korelasi ( $\mathbf{r}$ )}

Koefisien korelasi merupakan ukuran korelasi secara linear antara dua variable. Adapun skala kekuatan hubungan antar variable disajikan pada tabel dibawah ini::

Tabel 6. Tabel hubungan

\begin{tabular}{cc}
\hline Koefisien korelasi $(\mathbf{r})$ & Hubungan \\
\hline $0,00-0,199$ & Sangat rendah \\
$0,20-0,399$ & Rendah \\
$0,40-0,599$ & Sedang \\
$0,60-0,799$ & Kuat \\
$0,80-\ldots 1,0$ & Sangat kuat
\end{tabular}

Sumber: Data diolah, 2021

Dari Tabel 6 diatas disajikan tentang skala koefisien korelasi dan jenis kekuatan hubungan yang ditetapkan untuk melihat hubungan antar variabel. Selanjutnya, Untuk 
analisis data hasil penelitian menggunakan alat regresi linier berganda yang dijelaskan pada Tabel 7 sebagai berikut:

Tabel 7. Koefisien SPSS

Coefficients $^{\mathrm{a}}$

\begin{tabular}{|c|c|c|c|c|c|c|}
\hline & \multirow[t]{2}{*}{ Model } & & $\begin{array}{r}\text { Unstandardized } \\
\text { Coefficients } \\
\end{array}$ & $\begin{array}{r}\text { Standardized } \\
\text { Coefficients } \\
\end{array}$ & \multirow[t]{2}{*}{$\mathbf{t}$} & \multirow[t]{2}{*}{ Sig. } \\
\hline & & B & Std. Error & Beta & & \\
\hline \multirow[t]{3}{*}{1} & (Constant) & .034 & .165 & & .208 & .836 \\
\hline & $\mathrm{X} 1$ & .774 & .063 & .624 & 12.304 & .000 \\
\hline & $\mathrm{X} 2$ & .633 & .085 & .377 & 7.424 & .000 \\
\hline
\end{tabular}

a. Dependent Variable: Y

Sumber : Data diolah, 2021

Dari data Tabel 7 terlihat bahwa konstanta bernilai sebesar 0,034 dapat di artikan bahwa Kinerja Karyawan (Y) akan bernilai 0,034 jika variabel Reward dan Punishment adalah tidak ada (0) atau tetap. Sementara itu, koefesien regresi variabel Reward (X1) bernilai positif sebesar 0,774 artinya setiap penambahan Reward (X1) mengalami kenaikan satu satuan (1) maka akan menaikan kinerja karyawan sebesar 0,774 satuan dengan asumsi Variabel Punishment (X2) tetap. Yang artinya semakin tinggi Reward maka semakin naik Kinerja Karyawan yang diperoleh. Sedangkan, koefesien regresi variabel Punishment (X2) bernilai positif sebesar 0,633 artinya setiap penambahan Punishment (x2) mengalami kenaikan satu satuan (1) maka akan menaikkan kinerja karyawan sebesar 0,633 satuan dengan asumsi variabel reward (X1) tetap.

\section{Koefisien determinasi ( $\mathbf{R}^{\mathbf{2}}$ )}

Koefisien determinasi dilakukan untuk melihat seberapa besar kemampuan variabel independen menjelaskan variabel dependen penelitian. Koefisien determinasi dalam penelitian ini disajikan dalam Tabel 8 dibawah ini:

Tabel 8. Model summamry

\begin{tabular}{rrrrr}
\hline Model & R & R Square & Adjusted R Square & $\begin{array}{c}\text { Std. Error of the } \\
\text { Estimate }\end{array}$ \\
\hline 1 & $.993^{\mathrm{a}}$ & .987 & .987 & .48659 \\
\hline
\end{tabular}

a. Predictors: (constant), X2, X1

b. Dependent variable: Y

Sumber : Data diolah, 2021

Berdasarkan Tabel 8 terlihat bahwa angka $\mathrm{R}$ sebesar 0,993 dimana terjadi hubungan yang sangat kuat antara penghargaan dan sanksi terhadap kinerja karyawan. Koefisien Determinasi $\left(\mathrm{R}^{2}\right)$ terlihat besarnya pengaruh $\mathrm{X}$ terhadap variable $\mathrm{Y}$ secara bersama-sama. R Square sebesar 0,987, maka, $\mathrm{R}^{2}=0,987 ;(0,987$ x 100\% $)=98,7 \%$. Dengan artian bahwa sebesar 98,7 \% kinerja karyawan dipengaruhi oleh variasi perubahan variabel X1 dan X2, sedangkan sisanya $(100 \%-98,7 \%=1,3 \%)$ dipengaruhi oleh faktor-faktor penyebab lainnya yang tidak diteliti pada penelitian ini. 


\section{Uji hipotesis}

\section{Uji F (uji simultan)}

Berikut adalah nilai F Hitung dalam Penelitian ini yang tersaji pada Tabel 9 dibawah ini:

Tabel 9. Uji F

\begin{tabular}{llrrrrr}
\hline & Model & \multicolumn{1}{c}{$\begin{array}{c}\text { Sum of } \\
\text { Squares }\end{array}$} & df & \multicolumn{1}{c}{$\begin{array}{c}\text { Mean } \\
\text { Square }\end{array}$} & F & Sig. \\
\hline 1 & Regression & 1456.975 & 2 & 728.487 & 3076.773 & $.000^{\mathrm{b}}$ \\
& Residual & 19.415 & 82 & .237 & & \\
Total & 1476.390 & 84 & & & \\
\hline
\end{tabular}

a. Dependent Variable: Y

Sumber : Data diolah, 2021

Dari data Tabel 9, terlihat bahwa nilai $F_{\text {hitung }}$ sebesar 3076,77 dengan taraf signifikansi $F=0,00$. Dengan membandingkan nilai $F_{\text {hitung }}$ dan $F_{\text {tabel }}$ maka diperoleh sebuah kesimpulan. Cara menghitung $\mathrm{F}_{\text {table }}$ adalah $\mathrm{df} 1=(\mathrm{k}-1)$ dan $\mathrm{df} 2=(\mathrm{n}-\mathrm{k})$ dimana $(\mathrm{k})$ merupakan jumlah variabel (bebas + terikat) dan (n) adalah jumlah observasi/sampel pembentuk regresi. Kolom df 1 dan df 2 pada table F. Maka nilai df $1=(3-1)=2$ dan df $2=(85$ $-3)=82$ Dari hasil tersebut dapat diperoleh $F_{\text {tabel }}=3,108$. Jadi dapat disimpulkan bahwa Fhitung > Ftabel $(3076,77>3,108)$. Untuk lebih jelas dapat dilihat pada Gambar 3 dibawah ini:

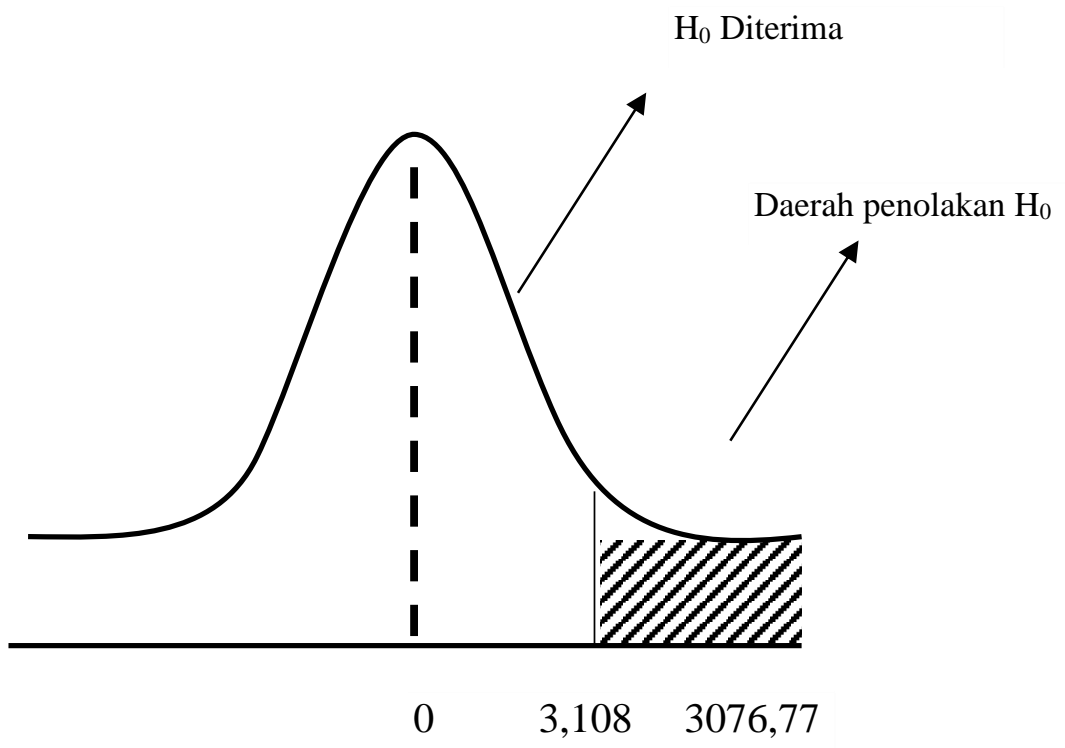

Gambar 3. Kurva normal Uji F

Dari Gambar 3 terlihat bahwa nilai signifikansi adalah dibawah 0.05 yang memiliki arti variabel bebas secara bersama-sama mempunyai pengaruh yang signifikan terhadap kinerja karyawan pada signifikansi 5\%, Sig F < 5\% $(0,00<0,05)$. Artinya bahwa secara bersama-sama Penghargaan dan sanksi berpengaruh signifikan terhadap kinerja karyawan. 


\section{KESIMPULAN DAN SARAN}

\section{Kesimpulan}

Koefisien Determinasi $\left(\mathrm{R}^{2}\right)$ menunjukkan besarnya pengaruh variable $\mathrm{X}$ terhadap variable $\mathrm{Y}$ secara bersama-sama dan dinyatakan dalam persentase. Pada table diatas menunjukan R Square sebesar 0,987, jika di persentasekan maka, $\mathrm{R}^{2}=0,987$; ( 0,987 $\mathrm{x} 100 \%)=98,7 \%$. Angka tersebut mempunyai arti bahwa sebesar 98,7 \% Kinerja Karyawan dipengaruhi oleh variasi perubahan variabel Reward (X1) dan sanksi (X2), sedangkan sisanya $(100 \%-98,7 \%=1,3 \%)$ dipengaruhi oleh faktor-faktor penyebab lainnya yang tidak diteliti pada penelitian ini.

Dari hasil tersebut dapat diperoleh $\mathrm{F}_{\text {tabel }}=3,108$. Jadi dapat disimpulkan bahwa $\mathrm{F}^{\text {hitung }}>\mathrm{F}_{\text {tabel }}(3076,77>3,108)$. Nilai signifikansi adalah dibawah 0.05 yang menunjukkan bahwa variabel bebas secara Bersama-sama mempunyai pengaruh yang signifikan terhadap Kinerja Karyawan pada signifikansi 5\%, Sig F < 5\% $(0,00<0,05)$. Artinya bahwa secara bersama-sama Penghargaan dan Sanksi berpengaruh signifikan terhadap kinerja karyawan.

\section{Saran}

Saran penelitian penghargaan dan sanksi aspek yang sangat penting yang harus diperhatikan di Instansi dalam kinerja karyawan. Karena Reward bisa mewujudkan asumsiasumsi dasar anggota Instansi tentang segala sesuatu semangat dan kepedulian dengan rasa memiliki.

\section{DAFTAR PUSTAKA}

Adolfina, R. S., \& Uhing, Y. (2017). The effect of reward and punishment on employees performance of Sutanraja Hotel Amurang. Emba, 5(2), 1050-1059.

Afrizal, D. (2018). Analisis kinerja birokrasi publik pada Dinas Sosial Kota Dumai. SOROT, 13(1), 53-62. https://doi.org/https://doi.org/10.31258/sorot.13.1.5655

Afrizal, Dedy, Al-Amaren, E. M., \& Yusuf, I. M. (2021). The participation of the breeders : regional regulation of Dumai City Concerning Livestock and Pets. Yustisia Jurnal Hukum, 10(1), 84. https://doi.org/10.20961/yustisia.v10i1.49001

Astuti, W. S., Sjahruddin, H., \& Purnomo, S. (2018). Pengaruh reward dan punishment terhadap kinerja karyawan. Organisasi Dan Manajemen, 1(1), 31-46.

Ferdinand, N., \& Satibi, A. (2021). Pengaruh Penghargaan terhadap kinerja karyawan minimarket. Jurnal Manajemen Bisnis dan Keuangan, 2(1), 30-37. https://doi.org/ 10.51805/jmbk.v2i1.31

Hidayat, F. (2018). Pengaruh reward dan punishment terhadap kinerja karyawan dengan disiplin kerja sebagai variabel intervening di waroeng spesial sambal Yogyakarta. Skripsi, Universitas Islam Indonesia: Yogyakarta

Kadarisman, M. (2012). Pengertian dan filosofi manajemen kompensasi. In manajemen sumber daya manusia.

Kumentas, C. (2013). Pengaruh TQM, sistem pengukuran kinerja dan penghargaan terhadap kinerja manajerial Pt. Pos Indonesia. Jurnal Riset Ekonomi, Manajemen, Bisnis dan Akuntansi, 1(3), 796-805. https://doi.org/10.35794/ emba.v1i3.1888

Mangkunegara, A. P., \& Prabu, A. (2012). Evaluasi kinerja SDM, cetakan keenam. Refika Aditama: Jawa Barat 
Pramesti, R. A., Sambul, S. A. P., \& Rumawas, W. (2019). Pengaruh reward dan punishment terhadap kinerja karyawan KFC Artha Gading. Jurnal Administrasi Bisnis, 9(1), 57. https://doi.org/10.35797/jab.9.1.2019.23557.57-63

Sugiyono. (2013). Metode penelitian manajemen. CV. Alfabeta: Jakarta

Wirawan, A., \& Afani, I. N. (2018). Pengaruh Reward dan punishment terhadap kinerja dan motivasi karyawan pada Cv Media Kreasi Bangsa. Journal of Applied Business Administration, 2(2), 242-257. https://doi.org/10.30871/jaba.v2i2. 1124

Yani, D. A. (2021). Pengaruh Penghargaan dan budaya organisasi terhadap kinerja karyawan pada PT. Widya Pratama Perkasa. Jurnal Manajemen Dan Bisnis, 11(2), 77-90. 